\title{
RESIDUAL BEARING CAPACITY OF REINFORCED CONCRETE COLUMNS AFTER CLOSE-IN DETONATIONS: EXPERIMENTAL AND NUMERICAL INVESTIGATIONS.
}

\author{
M. ARLERY \& C. PONTIROLI \\ CEA, DAM, GRAMAT, F-46500 Gramat, France.
}

\begin{abstract}
Post-blast residual bearing capacity of columns is a crucial issue for the assessment of progressive collapse risk on multi-storied buildings.

In this paper, experiments of small-scale near-field detonation on reinforced concrete columns are presented, during which pressure loadings and dynamic displacements are measured. Post-blast residual bearing capacities of the columns are also measured by quasi-static compressive tests up to failure. Experimental results show gradual transition from global to local damage, but strongly non-linear loss of capacity with stand-off distance reduction.

Numerical simulations are performed to simulate both blast and compressive tests. First, the complex dynamic loading and response of the columns can only be correctly reproduced thanks to detailed dynamic 3D fluid calculation, performed with OURANOS code [26], and comprehensive concrete behavior description with PRM model [29], implemented in ABAQUS-Explicit. Then, low loading rate calculations with ABAQUS-Explicit can reasonably restitute the quasi-static response of blastdamaged columns under increasing compressive load.
\end{abstract}

Keywords: Blast; Damage; Experience; Reinforced concrete column; Residual capacity; Simulation

\section{INTRODUCTION}

Reinforced concrete (RC) columns are one of the most important load-bearing elements, especially in high framed buildings. If one of them were intended to fail under blast load, the entire structure may progressively collapse if the construction has no sufficient alternate load path. Evaluating the residual capacity of blast damaged columns thus appears to be a crucial issue for the prediction of the overall post-blast resistance of a building. Although they are useful for design engineers, simplified methods based on single-degree-of-freedom (SDOF) analysis from blast-resistant design guidelines [1] are limited in the case of close-range detonations on stand-alone structures. 3D analysis of both the blast loading and the structural response can provide a better understanding of these configurations.

An extensive experimental work has been carried out to understand the behavior of RC columns since 1950's. Many researchers investigated the effects of slenderness, eccentricity of axial loading, or confinement and ductility produced by lateral reinforcement.

As described in [2], a column can fail because of either reaching the ultimate strength of the materials constituting the cross-section or an instability due to second-order effects. Columns with low slenderness are prone to fail by cross-section overload. For such failure, it is assumed that the longitudinal reinforcement of the section supports a part of the axial load up to a maximum load defined by either the buckling [3] or the plastic [4] capacity of the bars. Core concrete resistance can be enhanced by the passive confinement of transverse reinforcement, resulting in an increase in strength and deformation capacity of the columns [5-7]. However, concrete crushing under compressive load has been considered to be responsible for size effects reported in experimental investigations: capacity and ductility of the column are reduced when specimen size increases $[7,8]$. 
More recently, investigations on the effect of blast loading on $\mathrm{RC}$ columns were conducted. The complex failure mechanisms were identified and three different failure modes are commonly reported [9-12]: flexural mode with plastic hinges formation, shear mode with diagonal cracks and potential longitudinal bars breaking-off, and localized mode (concrete spalling, cratering, crushing and possible direct shear failure).

However, nor the maximum deflection commonly used in SDOF analyses, neither the visualization of final damage patterns does allow meaningful estimation of overall damage. A more relevant criterion, proposed in [12], is based on the residual axial load-carrying capacity of the column. This criterion has the advantages to be directly related to the main structural functionality of the column and to be independent to the blast damage mode(s).

This approach, which requires to perform post-blast compression analysis, has been adopted in several numerical studies [12-15], but more rarely in experimental works [3, 11, 16]. Furthermore, even if the numerical and experimental maximal strengths are successfully compared on undamaged columns [17-19], there is a lack of comparison on residual strength of blast-damaged columns.

The present study focuses on experimental and numerical investigations of the residual bearing capacity of RC columns after close-in detonation. This work was initiated within the SPIRIT Project of the 7th Framework Program of the European Union [20]. A numerical procedure was proposed to simulate the behavior of blasted structures and to estimate their residual bearing capacity in a generic high-rise building [21]. As in other works [12-15], a parametric study was also performed to extract an analytical formula quantifying the column's damage level as a function of columns' dimensions, concrete strength, charge mass and standoff distance.

A first experimental program was then carried out on small-scaled RC columns and numerical simulations showed the capacity to catch different concrete damage mechanisms [22]. Further experimental work was performed with an improved set up, allowing the application of a service axial load to the column prior to the blast [23]. These experiments are presented here, together with quasi-static compressive tests performed on blast-damaged columns. Numerical simulations are also presented which simulate both blast and compressive tests.

\section{EXPERIMENTAL FRAMEWORK}

\subsection{Experimental setups}

\subsubsection{Column specimen}

Tested columns are described on Fig. 1a. Geometrical dimensions are 100 x $100 \mathrm{~mm}^{2}$ of square cross section, $1000 \mathrm{~mm}$ in length and $10 \mathrm{~mm}$ of concrete cover thickness. Longitudinal reinforcement consists in four $8 \mathrm{~mm}$ diameter bars. Transverse reinforcement is insured by $6 \mathrm{~mm}$ diameter stirrups, spacing every $50 \mathrm{~mm}$ near columns ends and $100 \mathrm{~mm}$ in between. Traction tests were performed on longitudinal bars to determine yield stress, ultimate strength and strain, respectively equal to $561 \mathrm{MPa}, 665 \mathrm{MPa}$ and $18 \%$. Concrete with standard compressive strength from 25 to $30 \mathrm{MPa}$ is used. The concrete mixture, called "R30A7", was defined and tested for several years by CEA-Gramat and researching partners [24, 25].

\subsubsection{Blast tests}

Blast tests experimental setup is presented on Fig. 1b. For test, three columns are positioned 120 degrees from each other, around a few hundred grams of spherical explosive charge hold 
(a)

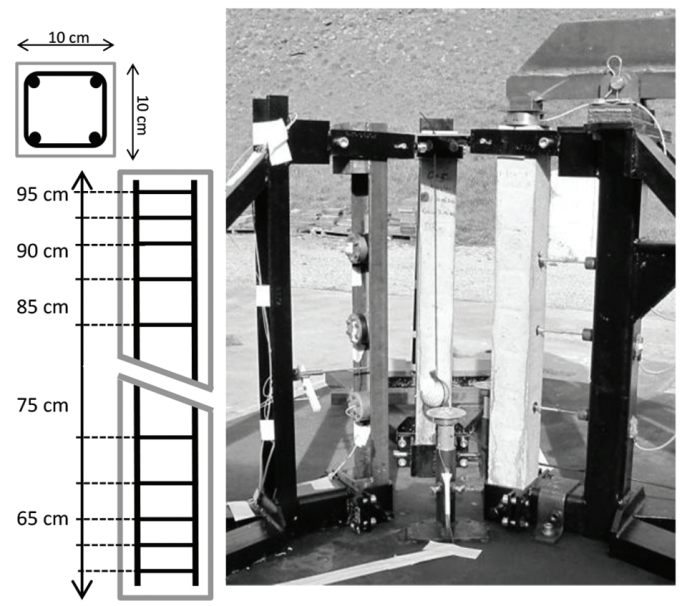

(c)

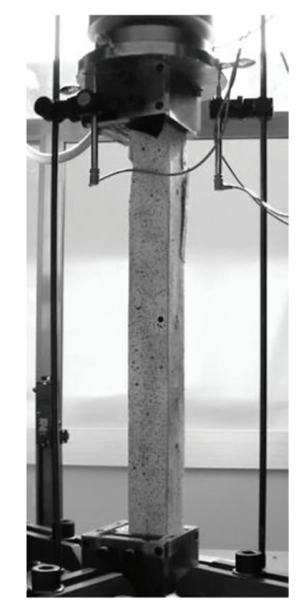

Figure 1: Experimental setups (a) Column dimension and reinforcement details; (b) Blast tests; (c) Post-blast uniaxial compressive tests.

on $30 \mathrm{~cm}$ above ground. Top ends of the columns are simply supported whereas bottom ends are fixed in rigid steel caps. A vertical axial load close to $60 \mathrm{kN}$ (service ratio of about 20\%), is applied by a pneumatic jack to one of the column. Standoff distances from charge center to front face of the columns varied from 10 to $18 \mathrm{~cm}$.

Instrumentation consisted in linear variable differential transducers (LVDT) recording horizontal displacements of the column's rear face at different span heights, pressure sensors measuring the incident blast pressure and the applied pressure on column's front and a load sensor checking the axial load applied by the jack.

\subsubsection{Post-blast uniaxial compression tests}

Uniaxial compression tests experimental setup is presented on Fig. 1c. The damaged columns were positioned in the uniaxial compressive testing machine and loaded until failure. To ensure proper load transmission and avoid slipping during the test, the column's top and bottom ends were fixed in rigid steel caps.

As the compressive machine site was located nearby the blast site, the columns were cautiously handled to avoid any additional damage. However, this move induced the removal of service axial load on the concerned columns. Their stress state at the starting of compressive tests was thus released and not identically recovered at the beginning of compression, as the top end supporting conditions differed from blast to compressive setups. The effect on final residual capacity is provisionally supposed to be low, but will be further quantified by numerical investigations.

The compressive machine was driven with a displacement mode, at a rate of $0.24 \mathrm{~mm} / \mathrm{mn}$. Three linear variable differential transducers (LVDT) recorded the vertical end-to-end displacements of the column. The averaged displacement served as reference.

\subsection{Experimental results}

Experimental blast conditions and main results are reported in Table 1, where dynamic and permanent deflections are measured at mid-height of the column (detailed results in [23]). 
Table 1: Experimental blast conditions and main results

\begin{tabular}{lllllll}
\hline Specimen & $\begin{array}{l}\text { Axial load } \\
(\mathbf{k N})\end{array}$ & $\begin{array}{l}\text { Standoff } \\
\text { distance } \\
(\mathbf{c m})\end{array}$ & $\begin{array}{l}\text { Damage } \\
\text { range }\end{array}$ & $\begin{array}{l}\text { Dynamic } \\
\text { deflection } \\
(\mathbf{m m})\end{array}$ & $\begin{array}{l}\text { Permanent } \\
\text { deflection } \\
(\mathbf{m m})\end{array}$ & $\begin{array}{l}\text { Residual } \\
\text { capacity } \\
(\mathbf{k N})\end{array}$ \\
\hline C4 & 60. & 18 & very slight & 5.5 & 0.5 & 313 \\
C5 & - & 18 & slight & 8.8 & 1.6 & 297 \\
C18 & 62. & 15 & moderate & 10.5 & 5.4 & 164 \\
C17 & - & 15 & moderate & 10.0 & 2.6 & 239 \\
C12 & - & 13 & heavy & no measure & no measure & 170 \\
C20 & 63. & 10 & severe & no measure & 57 & 8 \\
C19 & - & 10 & severe & 53 & 34 & 11 \\
\hline
\end{tabular}

\subsubsection{Blast induced damage patterns}

Figure 2a presents post-blast side-views for different standoff distances for columns without (on left) or with service axial loads (on right).

As can be observed, columns located at $18 \mathrm{~cm}$ from the charge suffered only minor damage, characterized by horizontal and diagonal cracks. The density of cracks is noticeably lower for the axially-loaded column C4 than for the non-loaded column C5. At $15 \mathrm{~cm}$ standoff distance, local effects are also observed, with concrete spallation on rear face and little concrete cratering on front face. These effects are more extended for the axially-loaded column $\mathrm{C} 18$ than the non-loaded C17. Column C12 located at $13 \mathrm{~cm}$ standoff distance presents wider spalling and cratering areas, as well as covering concrete exfoliation on side faces. Finally, at closest distance of $10 \mathrm{~cm}$, columns C19 and C20 are severely damaged next to the charge, with ejection of a large part of initial concrete volume and large lateral deformations of longitudinal reinforcement bars.

These observations demonstrate that with decreasing standoff distance, the column is gradually translating from a global bending response mode to a local response mode associated to severe damaging of materials next to the charge location.

\subsubsection{Dynamic displacements under blast}

Mid-span displacements histories of non-loaded and axially loaded columns are compared on Fig. $2 \mathrm{~b}$ for standoff distances of $18 \mathrm{~cm}$ (graph on left) and $15 \mathrm{~cm}$ (graph on right). Signals are characterized by a maximal dynamic deflection, followed by damped oscillations around the final residual deflection value. The non-zero initial deflection measured for axially loaded columns just before blast is due to the elastic lateral deformation of the column under service axial compressive load.

At a standoff distance of $18 \mathrm{~cm}$, both dynamic and residual deflections are less important for the axially loaded column C4 than for the non-loaded column C5. On the reverse, at a standoff distance of $15 \mathrm{~cm}$, the axially loaded column C18 suffered larger dynamic and residual deflections.

The results show that the service axial load increases the column's blast resistance for limited deflections, but reduces this resistance for larger deflections.

\subsubsection{Residual load bearing capacity}

Experimental compressive load versus vertical displacement curves are presented on Fig. 3a for blast-damaged columns (graph on right) and two referring undamaged columns C10 and 
(a)
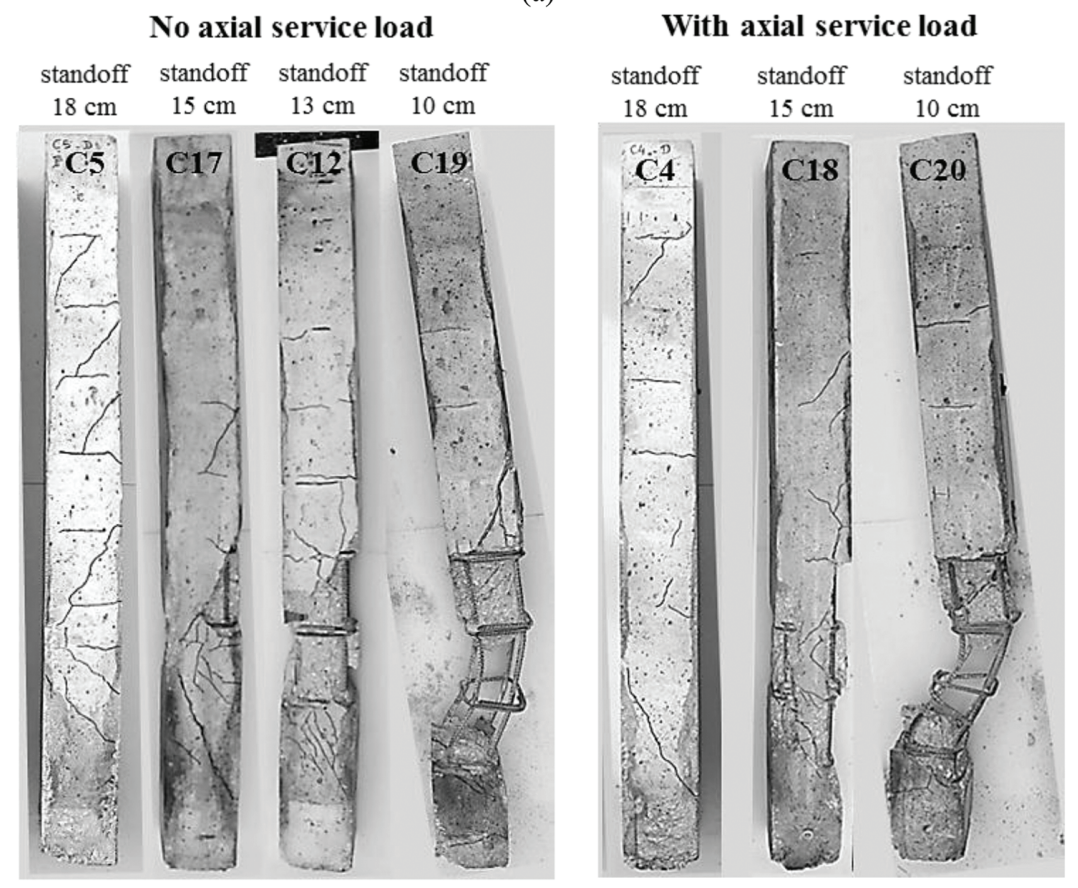

(b)
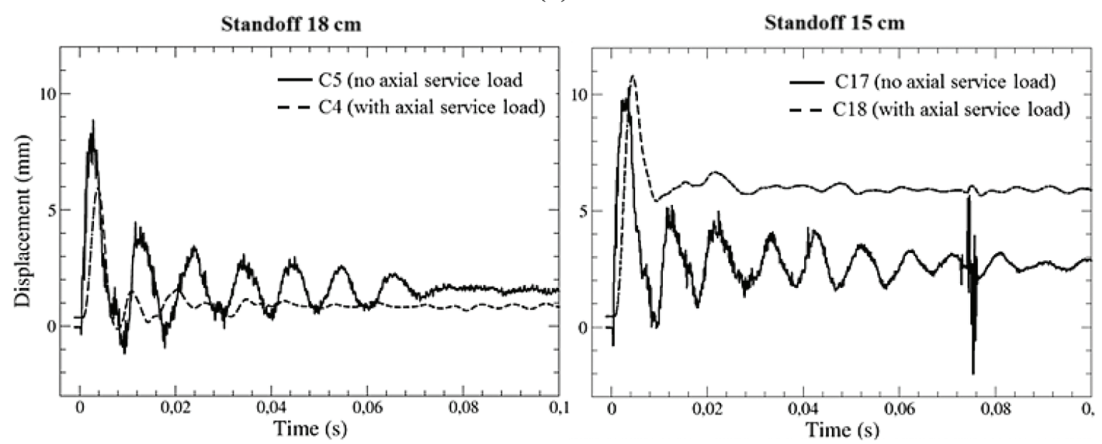

Figure 2: Experimental blast results (a) Side views of blast-damaged columns; (b) Displacement time histories at mid-height.

C11 (graph on left). Loading-unloading cycles, performed at early stage of the test, can be seen on some of these curves. Typical final failure patterns under compressive load are shown on Fig. $3 \mathrm{~b}$ for both undamaged and blast-damaged columns.

Loading curves obtained on undamaged columns are quite similar. Pre-peak reload slopes after unloading cycles are the same, indicating that initial column's strengths are comparable. Maximal loads differ of only $3 \mathrm{kN}$, for an averaged value of $312.5 \mathrm{kN}$. Post-peak slopes are slightly different. For both columns, a fine network of vertical cracks was observed as the maximal load approached. Then, the cover concrete started to fall, before the four longitudinal rebars finally buckle in a relative symmetrical way.

Loading curves obtained on blast-damaged columns clearly show the gradual decrease of both initial strengths and residual capacities with standoff distance reduction. Moreover, 
(a)

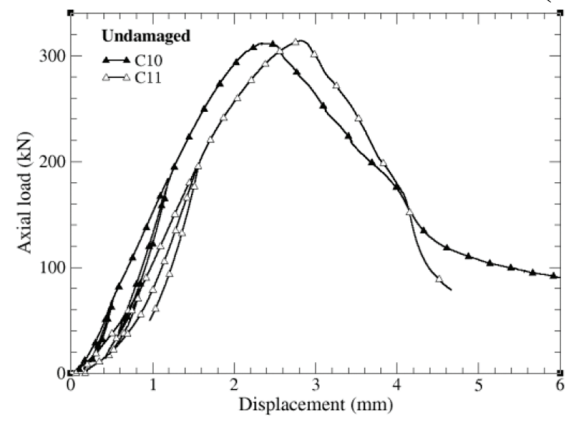

(b)
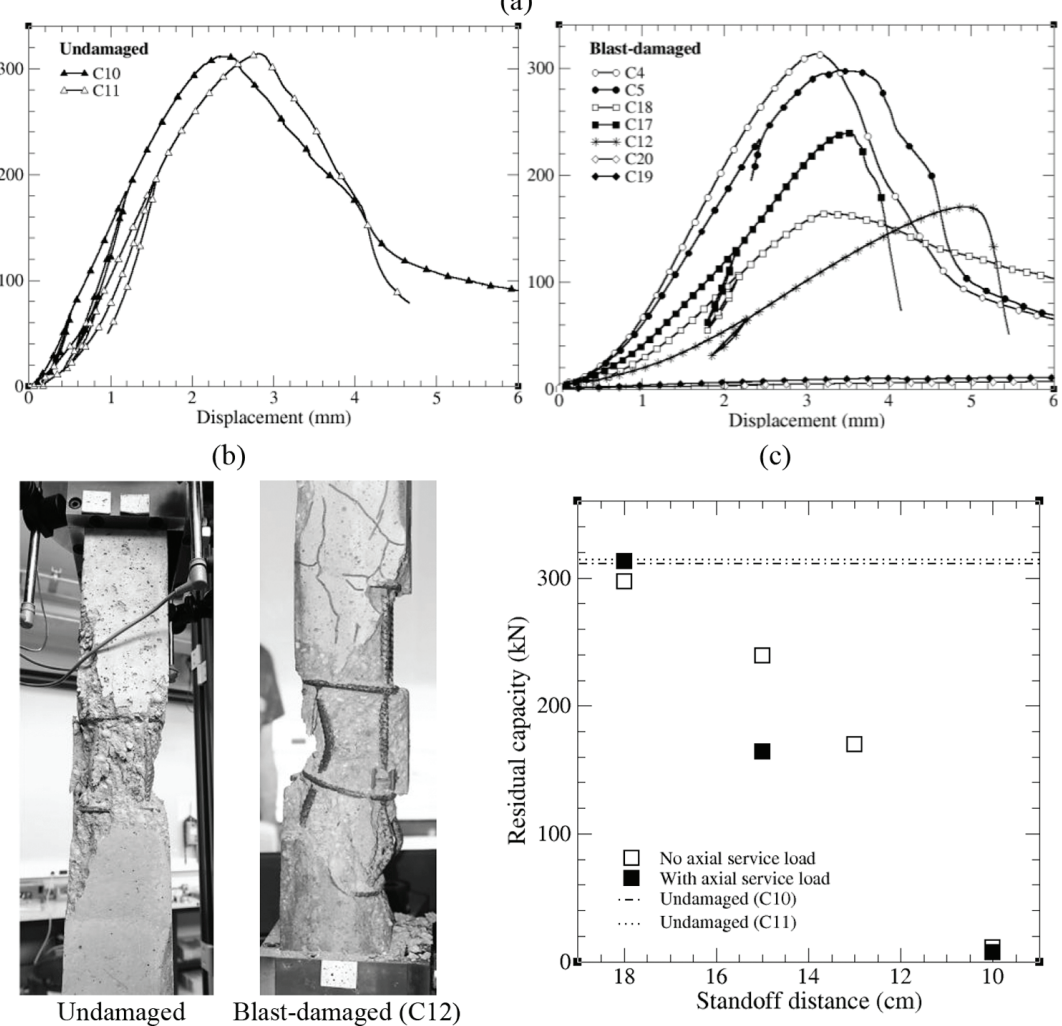

(c)

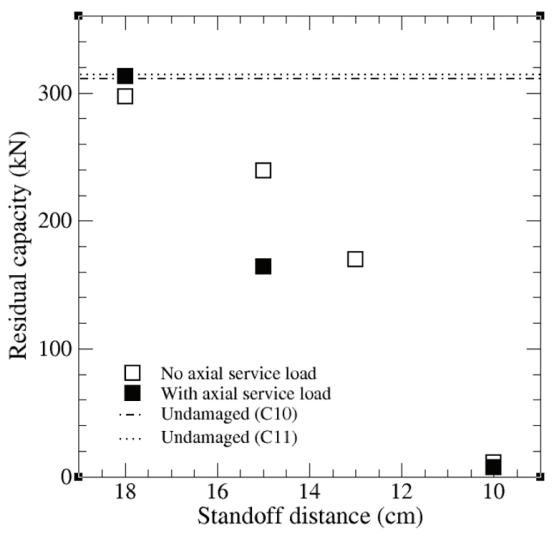

Figure 3: Experimental post-blast axial compression results (a) Axial load vs displacement curves; (b) Typical failure patterns; (c) Residual capacity vs explosive standoff distance

significant differences are observed between non- and axially loaded columns at the same standoff distance. At $18 \mathrm{~cm}$, the capacity of the axially loaded column $\mathrm{C} 4$ is just slightly lower than the undamaged columns $\mathrm{C} 10$ and $\mathrm{C} 11$. At $15 \mathrm{~cm}$, the loaded column $\mathrm{C} 18$ has a significantly lower residual capacity than the unloaded column C18. Finally, at $10 \mathrm{~cm}$, both types of columns have almost no more residual capacity.

These results are perfectly correlated to both displacements variations during blast and damage levels observed after the blast tests.

The evolution of post-blast residual bearing capacity of the columns with decreasing standoff distance is finally plotted on Fig. 3c. The column resistance is decreasing very rapidly. In the present small-scaled experiments, the total loss of bearing capacity occurs for a reduction in exposure distance of only $8 \mathrm{~cm}$.

\section{SIMULATIONS}

\subsection{Numerical procedure}

As it has already been described in details by the authors [21, 22], the adopted numerical methodology is only briefly described in this paper. 
3D fluid dynamic calculations are first performed with our code OURANOS [26], in order to get an accurate evaluation of the complex blast load applied to the structure by the close-in explosive detonation. As demonstrated in [23], this load evaluation is preferable to the faster but simpler evaluation performed with the analytical tool ConWep.

Then, the behavior of the column is evaluated with the ABAQUS-Explicit finite element code in three successive steps :

- in a first step, a compressive axial load is applied on columns to impose service load, in a very gradual way in order to avoid dynamic effects due to the explicit scheme of the analysis,

- in a second step, the dynamic response of the column to the blast load is calculated, until static equilibrium is recovered,

- in a third step, a gradual compressive axial load is applied to the blast-damaged column up to failure, in order to estimate its residual bearing capacity.

Concrete behavior is described by the PRM concrete model (Pontiroli, Rouquand \& Mazars [27, 28]), developed at CEA-Gramat for several decades and routinely used in ABAQUS-Explicit to simulate the concrete response under a large range of dynamic loadings [29]. This model includes two scalar damage variables, determining the loss of stiffness under respectively tensile and compressive loading. For intense loading, the coupling with the plastic Krieg-Swenson-Taylor model [30] accounts for mechanisms occurring at high pressure levels: pore compaction, shear plastic limit evolution and water content effects.

Steel behavior is described by the Johnson Cook dynamic failure model [31], which includes an isotropic hardening mechanism with strain rate dependency and a damage mechanism. The model's static parameters have been determined from uniaxial tensile tests performed on reinforcement bars.

\subsection{Numerical results and comparison to experience}

\subsubsection{Dynamic response under blast}

Typical comparisons of post-blast experimental and numerical damage features are presented on Fig. $4 \mathrm{a}$, where numerical damage scaling refers to maximal positive extension in concrete above $1 \%$.

At a standoff distance of $10 \mathrm{~cm}$, local damage obtained numerically is close to the severe observed one, with concrete perforation and large lateral deformation of longitudinal bars. At a standoff distance of $15 \mathrm{~cm}$, numerical damage features are also consistent with the observations : conic concentration next to the charge, eroding effects on side face, and main front transversal cracks in upper part of the column.

Local concrete exfoliation is generally underestimated by the calculations. This result is attributed to the supposed perfect bond between concrete and steel and/or the numerical erosion criterion intentionally limited, in order to keep a correct blast-loading on the structure.

Dynamic experimental and numerical displacements time histories are compared on Fig. $4 \mathrm{~b}$ for standoff distances of $18 \mathrm{~cm}$ and $15 \mathrm{~cm}$. Good agreement is achieved on maximal deflections, but the correlation is less satisfying on post-peak damping processes and residual deflections. The calculated damping is the accumulation of material internal friction, friction induced by the contact between the column and its supporting, and an additional artificial damping. The last one, modelled as a viscous pressure, is necessary to 
(a)

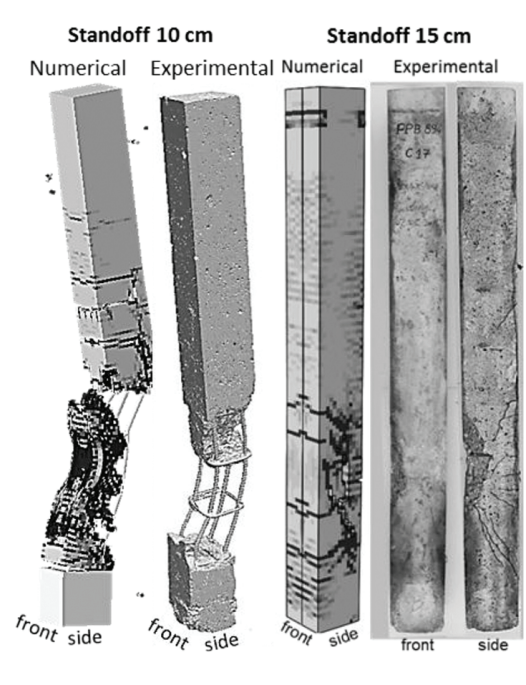

(b)
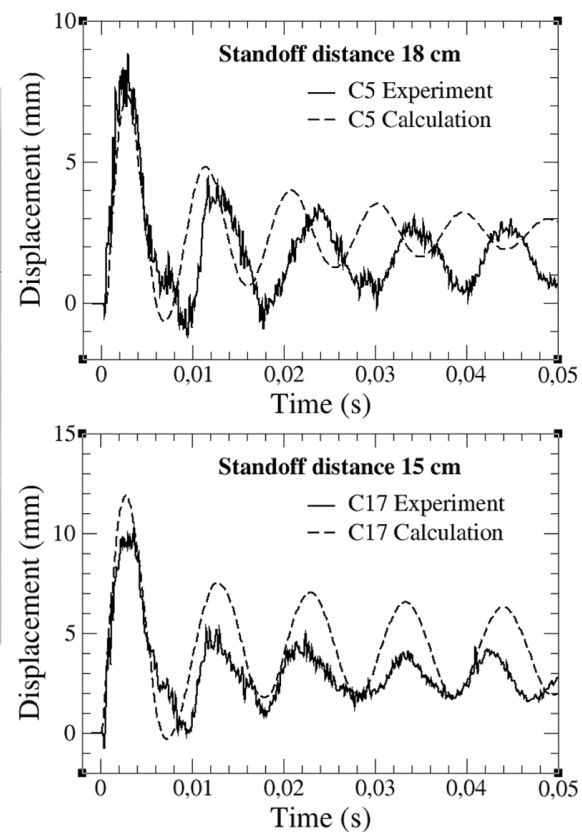

Figure 4: Comparison of measured and calculated blast behavior (a) post-blast damage patterns; (b) dynamic displacements at mid span

damp out dynamic effects and reach static equilibrium in an acceptable number of increments. One difficulty is to choose the appropriate time of application and value for this viscosity, otherwise significant modifications may be introduced in the structural response.

\subsubsection{Compression of undamaged and blast-damaged columns}

Experimental and numerical axial loading curves up to failure are compared on Fig. 5 for undamaged columns C13 and C16 (graph on left) and blast-damaged columns C5 and C17 (graph on right).

Experimental results on undamaged columns were obtained during the first experimental program with a concrete compressive strength of $25 \mathrm{MPa}$. Initial strength after unloading cycle, maximal strength, and post-peak slopes are similar for the two specimens.

Two calculations are presented: in the called "ideal" conditions, the axial load is perfectly concentric and the concrete properties are uniform in the whole column, whereas in the called "non-ideal" conditions a slight eccentricity in introduced to simulate geometrical imperfections of the column and small heterogeneities of concrete compressive strength are randomly distributed in the column to simulate materials initial defects. The transition from "ideal" to "non-ideal" conditions reduces the maximal strength and softens the post-peak response of the column. "Non-ideal" calculation is better correlated to experience.

Results obtained on damaged columns were obtained with a concrete compressive strength of $30 \mathrm{MPa}$. For both tested columns, the calculated residual bearing capacity is significantly lower than measured. At the moment, this gap is attributed to the over-estimated calculated post-blast residual eccentricities of the columns. However, further work is needed for a better 
(a)

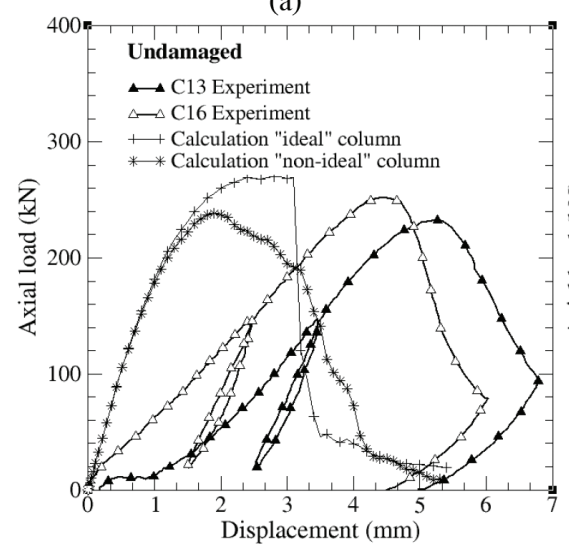

(b)

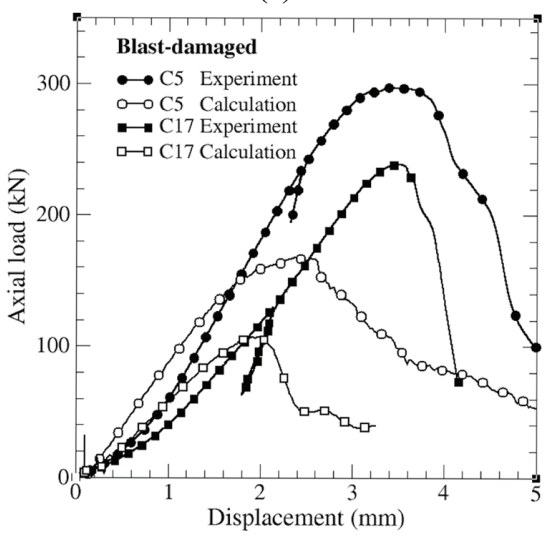

Figure 5: Comparison of measured and calculated axial compression behavior (a) undamaged columns C13 and C16 with $20 \mathrm{MPa}$ concrete; (b) blast-damaged columns C5 and C17 with $30 \mathrm{MPa}$ concrete.

understanding and possible improvement in the restitution of post-blast column's residual deflections.

\section{CONCLUSION}

In this work, experimental and numerical investigations are presented on the residual bearing capacity of small-scaled RC columns subjected to close-in detonation at various standoff distances.

Experimental results clearly show the effect of the column's service axial load on both dynamic response under blast and post-blast residual capacity: the column's resistance is enhanced for limited deflections, but reduced for larger deflections. It is also shown that the column residual capacity decreases from nearly nominal to almost no more bearing in a very short range of standoff distance. However, in the intermediate standoff range the column has a significant residual capacity, which could be decisive in the overall post-blast resistance of the whole building. As the tests are scaled, the full-scale transposition of post-blast capacities should account for size effects affecting both local response under very short range blast load and axial compressive resistance, where failure is initiated within the concrete.

Numerical calculations require preliminary 3D fluid dynamic calculations for an accurate evaluation of blast load applied on the structure. Subsequent finite element simulations of the column's response, using the PRM concrete model developed at CEA-Gramat, demonstrate the capacity of the adopted multi-stages procedure. The different damage mechanisms under blast are reproduced : from predominant global flexion at larger standoff distances to local material damage at shortest standoff distances. The restitution of dynamic displacements under blast is particularly satisfying maximal deflections. Discrepancies on residual deflections are noted and attributed to the high sensitivity of post-peak structural damping process to numerical parameters. A good correlation is also obtained on loading curves of undamaged columns under axial compressive load up to failure. First simulations performed on blastdamaged columns led to a significant under-estimation of experimental residual capacities, attributed for the moment to the overestimation of final post-blast eccentricities. 


\section{ACKNOWLEDGEMENTS}

This work was supported by the French Ministry of Defence, through DGA/UM-HMI. The authors gratefully acknowledge the CEA-Gramat experimental team members for their contribution to this work. The authors are also grateful to their partners from "Soils, solids, structures and risks" laboratory of University of Grenoble-Alpes.

\section{REFERENCES}

[1] Army Technical Manual 5-855-1, Fundamentals of Protective Design for Conventional Weapons. Headquarters, Department of the Army, 1986.

[2] Pallarés, L., Bonet, J.L., Miguel, P.F. \& Fernandez Prada, M.A., Experimental research on high strength concrete slender columns subjected to compression and biaxial bending forces. Engineering Structures, 30, pp. 1879-1894, 2008.

https://doi.org/10.1016/j.engstruct.2007.12.005

[3] Fujikake, K. \& Aemlaor, P., Damage of reinforced concrete columns under demolition blasting. Engineering Structures, 55, pp. 116-125, 2013. https://doi.org/10.1016/j.engstruct.2011.08.038

[4] Mac-Gregor, J.G.G., Reinforced Concrete: Mechanics and Design. Professional Technical Reference. Englewood Cliffs, NJ: Prentice-Hall, 1997.

[5] Cervenka, J. \& Papanikolaou, V.K., Three dimensional combined fracture-plastic material model for concrete. International Journal of Plasticity, 24, pp. 2192-2220, 2008. https://doi.org/10.1016/j.ijplas.2008.01.004

[6] Doran, B., Numerical simulation of conventional RC columns under concentric loading. Materials and Design, 30, pp. 2158-2166, 2009.

https://doi.org/10.1016/j.matdes.2008.08.033

[7] Carpinteri, A., Corrado, M., Goso, G. \& Paggi, M., Size-scale effects on interaction diagrams for reinforced concrete columns. Construction and Building Materials, 27, pp. 271-279, 2012.

https://doi.org/10.1016/j.conbuildmat.2011.07.047

[8] Sener, S., Barr, B.I. \& Abusiaf, H., Size effects in axially loaded reinforced concrete columns. Journal of Structural Engineering, 130(4), pp. 662-670, 2004.

https://doi.org/10.1061/(asce)0733-9445(2004)130:4(662)

[9] Yao, S.J., Zhang, D., Lua, F.Y., Wang, W. \& Chen, X.G., Damage features and dynamic response of RC beams under blast. Engineering Failure Analysis, 62, pp. 103-111, 2016.

https://doi.org/10.1016/j.engfailanal.2015.12.001

[10] Xu, J., Wu, C., Xiang, H., Su, Y., Li, Z.X, Fang, Q., Hao, H., Liu, Z., Zhang, Y. \& $\mathrm{Li}, \mathrm{J}$., Behaviour of ultra-high performance fibre reinforced concrete columns subjected to blast loading. Engineering Structures, 118, pp. 97-107, 2016. https://doi.org/10.1016/j.engstruct.2016.03.048

[11] Perea, A. \& Morrill, K., Component high explosive testing of bare and retrofitted columns. Proceedings of 17th International Symposium on Military Aspects of Blast and Shock, 2002.

[12] Shi, Y., Hao, H. \& Li, Z.X., Numerical derivation of pressure-impulse diagrams for prediction of RC column damage to blast load. International Journal of Impact Engineering, 35, pp. 1213-1227, 2008.

https://doi.org/10.1016/j.ijimpeng.2007.09.001 
[13] Bao, X. \& Li, B., Residual strength of blast damaged reinforced columns. International Journal of Impact Engineering, 37, pp. 295-308, 2010. https://doi.org/10.1016/j.ijimpeng.2009.04.003

[14] Mutalib, A.A. \& Hao, H., Development of P-I diagrams for FRP strengthened RC columns. Internationl Journal of Impact Engineering, 38, pp. 290-304, 2011. https://doi.org/10.1016/j.ijimpeng.2010.10.029

[15] Wu, K.C., Li, B. \& Tsai K.C., Residual axial compression capacity of localized blastdamaged RC columns. International Journal of Impact Engineering, 38, pp. 29-40, 2011. https://doi.org/10.1016/j.ijimpeng.2010.09.002

[16] Roller, C., Mayrhofer, C., Riedel, W. \& Thoma, K., Residual load capacity of exposed and hardened concrete columns under explosion loads. Engineering Structure, 55, pp. 66-72, 2013. https://doi.org/10.1016/j.engstruct.2011.12.004

[17] Montoya, E., Vecchio, F.J. \& Sheikh, S.A., Numerical evaluation of the behaviour of steel- and FRP-confined concrete columns using compression field modelling. Engineering Structure, 26, pp 1535-1545, 2004. https://doi.org/10.1016/j.engstruct.2004.05.009

[18] Majewski, T., Bobinski, J. \& Tejchman, J., FE analysis of failure behaviour of reinforced concrete columns under eccentric compression. Engineering Structures, 30, pp. 300-317, 2008. https://doi.org/10.1016/j.engstruct.2007.03.024

[19] Liu, J., Wang, X. \& Zhang, S., Behaviour of square tube reinforced-concrete short columns subjected to eccentric compression. Thin-Walled Structures, 91, pp. 108$115,2015$. https://doi.org/10.1016/j.tws.2015.01.023

[20] SPIRIT (Safety and Protection of built Infratsructure to Resist Integral Threat) -Framework program of the European Union, available at www.infrastructure-protection.eu

[21] Arlery, M., Rouquand, A. \& Chhim, S., Numerical dynamic simulation for the prediction of damage and loss of capacity of RC columns subjected to contact detonations. VIII International Conference on Fracture Mechanics of Concrete and Concrete Structures, Tolède, 2013.

[22] Pontiroli, C., Arlery, M. \& Rouquand, A., Damage and loss of capacity of RC columns subjected to close-in detonations : an experimental and numerical program. Proceedings of fifth International Workshop on Performance, Protection and Strengthening of Structures Under Extreme Loading, pp. 523-530, 2015.

[23] Arlery, M. \& Pontiroli, C., Experimental and numerical assessment of the damaging effects of close-in detonations on reinforced concrete columns. Proceedings of 17th International Symposium of the Interaction Effects of Munitions with Structures, 2017.

[24] Gabet, T., Malécot, Y. \& Daudeville, L., Triaxial behavior of concrete under high stresses: influence of the loading path on compaction and limit states. Cement and Concrete Research, 38(3), pp. 403-412, 2008. https://doi.org/10.1016/j.cemconres.2007.09.029

[25] Vu, X.H., Malecot, Y., Buzaud, E. \& Daudeville, L., Experimental analysis of concrete behavior under high confinement: effect of the saturation ratio. International Journal of Solids and Structures, 46, pp. 1105-1120, 2009. https://doi.org/10.1016/j.ijsolstr.2008.10.015 
[26] Jourdren, H., Sibeaud, J-M. \& Adamczewski-Cauret, M., Logiciel OURANOS: présentation générale et utilisation en détonique. Revue Scientifique et technique de la Défense, 4, pp. 51-58, 1995.

[27] Pontiroli, C., Comportement au souffle de structures en béton armé, analyse expérimentale et modélisation. Thèse de l'Ecole Normale Supérieure de Cachan, 1995.

[28] Mazars, J., Application de la mécanique de l'endommagement au comportement non-linéaire et à la rupture du béton de structure. Thèse de l'Université Paris VI, 1984.

[29] Pontiroli, C., Rouquand, A. \& Mazars, J., Predicting concrete behaviour from quasistatic loading to hypervelocity impact: an overview of the PRM model. European Journal of Environmental and Civil Engineering, 14, pp. 703-727, 2010. https://doi.org/10.3166/ejece.14.703-727

[30] Krieg, R.D., A simple constitutive description for soils and crushable foams, Sandia National Laboratories Report, SC-DR-72-0833, Albuquerque, New Mexico, 1978.

[31] Johnson, G.R. \& Cook, W.H., Fracture characteristics of three metals subjected to various strains, strain rates, temperatures and pressures. Engineering Fracture Mechanics, 21(1), pp. 31-48, 1985.

https://doi.org/10.1016/0013-7944(85)90052-9 